\title{
Excertos da História do Laboratorio Chymico da Universidade de Coimbra. Parte I: Período de 1820-1860*
}

\author{
Augusto Correia Cardoso \\ Departamento de Química da Universidade de Coimbra \\ cardoso@ci.uc.pt
}

\begin{abstract}
Excerpts from the History of Laboratorio Chymico of the University of Coimbra. Part I: Period 1820-1860 - At the beginning of 1774, between february and march, the walls of Laboratorio Chymico began to rise. It was centered in this building that Chemistry developed in the University of Coimbra, until being transferred to the new facilities of the University Campus in Rua Larga, in 1974. In the course of these 200 years there are periods, either in its beginning or already in the second half of the twentieth century, intensely studied in a historical perspective, shaped by the contexts of the time in European terms and in national terms. Other periods have been less studied. This is the case of the secular period from 1820 to 1930. From 1821 to 1840, Joaquim Franco Silva assumed the direction of the Chemical Laboratory. Following the Lutas Liberais, 1823 to 1834, the University of Coimbra was experiencing great difficulties, also reflected in the Chemical Laboratory. But its teachers sought to take care of the inventory of substances, instruments, and the library. At the same time they sought to follow the progress of chemistry and integrate them into the Laboratory. The "Reforma 1844" gave greater importance to the chemistry of the Curso Philosophico, which included, for the first time, some subdivisions of chemistry: Inorganic Chemistry and Organic Chemistry and Chemical Analysis.
\end{abstract}

$\mathrm{N}$ o início de 1774, entre fevereiro e março, as paredes do Laboratorio Chymico começaram a erguer-se. Foi centrada neste edifício que se desenvolveu a Química na Universidade de Coimbra, até vir a ser transferida para as novas instalações do Pólo I do Campus da Universidade na Rua Larga, em 1974. Neste percurso de 200 anos há períodos, quer no seu início quer já na segunda metade do século XX, intensamente estudados numa perspetiva histórica, moldada pelos contextos da época em termos europeus e em termos nacionais. Outros há menos estudados. É o caso do período secular de 1820 a 1930. De 1821 a 1840, Joaquim Franco Silva assume a direção do Laboratório Químico. Na sequência das Lutas Liberais de 1823 a 1834, a Universidade de Coimbra passa por grandes dificuldades, refletidas também no Laboratório Químico. Porém os seus professores procuraram cuidar do inventário em substâncias, instrumentos, bem como da biblioteca. Ao mesmo tempo procuraram acompanhar os progressos da química e integrá-los no Laboratório. A Reforma de 1844 veio dar maior importância à química do Curso Philosophico, que passa a integrar, pela primeira vez, algumas subdivisões da química: Química Inorgânica e Química Orgânica e Análise Química.

\section{Diretoria Joaquim Franco da Silva, 1821-1840}

Joaquim Franco da Silva (?-?), filho de José Franco, nasceu em Pero Negro, Sobral de Monte Agraço. Matriculou-se na Faculdade de Matemática, em 10 de outubro de 1799; realizou exame de admissão à Faculdade de Filosofia, em 5 junho de 1800; e, matriculou-se na Faculdade de Medicina, em 8 de outubro de 1802. Foi Bacharel formado em Filosofia, em 31 de julho de 1805. Na Congregação de 25 de novembro de 1805 «assinaram-se os pontos para a dissertação das Conclusões Magnas dos repetentes seguintes: (...) Joaquim Franco da Silva — An Basaltos aliquando productum sit vulcanicum? (Em que situações os basaltos são produtos de vulcanismo?)» [1], sendo aprovada em Congregação de 25 de maio de 1806 [2]. Foi habilitado a Licenciado, em 23 de julho de 1806 [3]; e Doutor em 28 do mesmo mês e ano. Bacharel formado em Medicina, em 4 de junho de 1813. Demonstrador sem indicação de cadeira em 1807-1808. Em dezembro de 1811, apresentou um requerimento para ser provido nas vagas de demonstradores «na forma das ordens régias, visto estar

\footnotetext{
* In Memoriam de Sebastião J. Formosinho (19.09.1943-19.12.2016)
}

para isso habilitado» [4]. Na sequência, em Congregação de 15 de janeiro de 1812, «mandou-se passar provimento a cada um dos demonstradores nomeados na Congregação antecedente a saber (...) o Doutor Joaquim Franco Silva para a Física» [5]. Na Congregação de 31 de julho de 1815, na distribuição de demonstradores «foi atribuído à Química, Joaquim Franco da Silva» [6]. Foi designado terceiro substituto de Metalurgia, de 1818 a 1822; quarto lente de Química, de 1822 a 1830; e, segundo lente de Química, em 1830-1831. O geógrafo italiano Adriano Balbi (1782-1848) considera-o: «naturaliste distingué, surtout dans la minéralogie») [7]. Passou a integrar a Congregação da Faculdade de Filosofia da Universidade de Coimbra, em novembro de 1818 [8]. No período de 1821 a 1840, como lente de Química mais antigo, exerceu as funções de Diretor do Laboratório Químico.

\section{Reforma de 1835 e a sua suspensão}

Em 1835, um ano após a subida de D. Maria II ao trono, por Decreto de 15 de fevereiro, passou da Repartição da Marinha para a Repartição dos Negócios do Reino onde ocorriam os assuntos respeitantes ao ensino, Agostinho José Freire (1780-1836), que procurou dar os pri- 
meiros passos para uma Reforma geral do ensino público, designando uma comissão, presidida por Francisco Manuel Trigoso de Aragão Morato (1777-1838), incumbida de propor ao Governo um plano de melhoramento do ensino público cujos trabalhos se saldaram por um relativo insucesso. Poucos meses depois, em 15 de julho, foi substituído por Rodrigo da Fonseca Magalhães (1787-1858), que seguindo uma política centralizadora, retirou todo o poder de decisão sobre política educativa à Universidade de Coimbra que, através da Junta da Diretoria Geral dos Estudos e Escolas do Reino, controlava, há décadas, o ensino a nível nacional, e cujas funções foram transferidas para um Conselho Superior de Instrução Pública, presidido pelo próprio ministro, que escolhia os seus membros. Propõe a redução das Faculdades de Cânones e Leis a uma só Faculdade, a supressão da Faculdade de Teologia, transferindo-se o ensino desta para os Seminários Episcopais, acrescentando a necessidade de se estabelecer cadeiras de Economia Política, Direito Constitucional Administrativo e Direito Comercial. Quanto às ciências Físicas e Matemáticas, anunciou o estabelecimento de duas escolas, uma em Lisboa e outra no Porto, onde estes conhecimentos, reformados e ampliados, fossem ensinados na sua teoria e aplicação. Deixava, unicamente, em Coimbra, as Faculdades de Matemática e de Filosofia, considerando-as como instituições de utilidade muito precária, pouco mais do que reduzidas à função de transmitirem alguns conhecimentos necessários aos estudantes destinados a seguir a Medicina, cujo melhoramento o Conselho deveria também refletir [9]. Rodrigues da Fonseca apenas geriu a pasta durante quatro meses, de julho a novembro de 1835, pois um pronunciamento militar levou à queda do governo do qual fazia parte. No seguimento da formação de um novo governo, Luís da Silva Mouzinho de Albuquerque (1792-1846), tomou posse da pasta. Apresentou às Cortes, em 26 de janeiro de 1836, uma lei que suspendeu a execução de uma parte das medidas decretadas pelo governo anterior alegando, designadamente, «as manifestações desfavoráveis da opinião pública, consubstanciadas nos "fundados protestos e reclamações da Universidade de Coimbra, e outras alegações e representações atendíveis chegadas ao governo» [10]. Porém, a proposta não foi discutida na Câmara nos meses que se seguiram. A demora levou a que o plano fosse vítima da instabilidade política que se continuava a viver em Portugal. Mouzinho de Albuquerque retirou-se, em abril de 1836.

No intermédio destes acontecimentos, em 22 de fevereiro de 1836, o Claustro Pleno da Universidade de Coimbra enviou às Câmaras Legislativas da Nação Portuguesa uma representação onde se referia: «A Universidade não se opõe a uma Reforma adequada ao melhoramento progressivo das Ciências, como injustamente se tem inculcado (...). Porém esta Reforma deverá separar as Ciências umas das outras, e assim, desmembrando as Faculdades, aniquilar a única Universidade do Reino? A razão e a experiência convencem evidentemente que não (...). Os representantes reconhecem que a Universidade tem tido épocas já mais, já menos florescentes: porém isso procede do concurso de diversas causas alheias da sua organização e situação; e das quais a maior parte são gerais a todo o Reino, e tem afetado igualmente todos os demais Estabelecimentos Literários dele (...). Consideremos agora os inconvenientes da intentada Reforma com relação especial a cada uma das Faculdades, que por ela se procuravam suprimir ou descolar, ponderando ao mesmo tempo os argumentos com que isto se tem procurado sustentar e defender (...). Faculdade Filosofia (...): O Laboratório Químico, criado e organizado pelo sábio Lente Tomé Rodrigues Sobral, tem uma excelente Oficina provida dos necessários utensílios e instrumentos, e um Gabinete abundante de tudo o necessário para a prática desta Ciência, carecendo apenas de uma forte pilha Elétrica e de poucos mais instrumentos modernos. Neste Laboratório se poderiam fazer muitas e grandes aplicações da Química às Artes, fornecendo-se-lhe os meios pecuniários para isso (...). Não são pois verdadeiros os fundamentos com que se tem procurado persuadir a conveniência da deslocação e desmembração da Universidade de Coimbra: e por isso os Representantes pedem à Sabedoria da Representação Nacional que haja de realizar quanto antes uma Reforma da Instrução Superior, sábia, perfeita, e adequada às circunstâncias do Reino: e esperam que esta Reforma, sendo assim feita, conservará a Universidade sem a desmembração ou deslocação projetada» [11].

\section{Reforma de 1836}

Em 1836 deu-se a designada "Revolução de Setembro”. Uma figura desta nova fase da vida nacional foi Manuel da Silva Passos (1801-1862), consagrado pela História com o nome de Passos Manuel, indicado Ministro do Reino do novo governo. Neste ano, publicou as Reformas dos estudos: primário (15 de novembro); secundário (17 do mesmo mês); e, superior (5 de dezembro). Para tal coordenação foi encarregado o então Vice-Reitor da Universidade de Coimbra, José Alexandre Caetano Campos e Almeida (1794-1850). Centremo-nos na reorganização "Da Universidade de Coimbra”, determinada pelo Decreto de 5 de dezembro de 1836: «atendendo a que os rápidos e multiplicados progressos que têm feito os estudos superiores, especialmente nos ramos das ciências naturais, depois da última reforma geral da Universidade de Coimbra (...): Hei por bem Aprovar e Decretar o Plano d'Estudos, que para aquela Universidade me foi apresentado pelo Vice-Reitor da mesma, o Doutor José Alexandre de Campos, e que vai assignado por Manuel da Silva Passos, Secretário de Estado dos Negócios do Reino» [12]. A remodelação mais importante irá cair sobre as Faculdades de Cânones e Leis que ficaram reduzidas à Faculdade de Direito. O Curso Filosófico estendeu-se de quatro para cinco anos e foi enriquecido com novas cadeiras mais especializadas. Separou a Mineralogia e a Zoologia em duas cadeiras; criou duas cadeiras especiais: uma de Agricultura e Economia rural e a outra de Tecnologia; alargou a Física; e, introduziu três cadeiras da Faculdade de Matemática e uma da Faculdade de Medicina. Estranhamente, a Reforma não contemplaria a Química que continuou reduzida, a uma só cadeira, agora no primeiro ano [13].

\section{A situação no Laboratório Químico}

Este período de agitado e instável contexto político e social não deixou de se manifestar na atividade do Laboratório Químico. Disso foi indicativo, em 1824, a res- 
posta do seu diretor a uma portaria do Reitor Principal Mendonça (Diogo de Castro Rio Furtado de Mendonça (1794-1827)), pedindo informações sobre: «1. ${ }^{\circ}$ o que se tem praticado na execução dos Estatutos L.3. ${ }^{\circ}$ P.3. ${ }^{a}$ TA $6 .^{\circ}$ Cap. 4. ${ }^{\circ}$; do Regimento do Operário e Demonstrador do Laboratório, ou de outra alguma providencia que tenha derrogado as antecedentes; $2 .^{\circ}$ que remeta o Mapa da despesa feita no Laboratório do valor dos géneros remetidos ao Dispensatório Farmacêutico, ou vendidos para outros quaisquer usos, pelo qual se possa saber o saldo a favor ou contra o Estabelecimento; $3 .^{\circ}$ que as reflexões que julgar convenientes a este respeito para que a Fazenda possa tirar lucro do Estabelecimento, ou pelo menos diminuir a despesa, em detrimento do Ensino Publico; $4 .^{\circ}$ finalmente que informe quais são as obrigações de cada um dos Oficiais empregados, e as horas em que devem satisfazer às mesmas obrigações» [14].

Franco da Silva respondeu nos seguintes termos: «Os Estatutos no lugar citado ordenam que haja um Laboratório no qual, além das experiências, se trabalhe oficialmente em fazer as preparações, que pertencem ao uso das Artes em geral, e da Medicina em particular; que o Lente respetivo tenha um subalterno denominado Operário Químico, para se empregar na demonstração das experiências, em ensinar os praticantes, e nas sobre ditas preparações como Mestre da Oficina, governando-se pelo que diz respeito às preparações para o uso da Medicina, pelas Direções da Congregação desta Faculdade, e pelo que respeita às preparações para o uso das Artes pela Congregação da Filosofia. Em virtude desta Lei se deliberou em diferentes Congregações que se dessem as providências necessárias para o Laboratório poder trabalhar em grande; até que na Congregação de 8 de janeiro de 1775 se conferiu a Manuel Joaquim Henriques Paiva o emprego de Operário com o interesse de quatro por cento, e com $240 \$ 000$ reis de ajuda do custo, enquanto não houvesse lucros suficientes. Mas ponderando-se em algumas Congregações ulteriores, que não tinha podido obter o privilégio das águas fortes, e do sublimado corrosivo, e que por essa causa o Laboratório não poderia tirar vantagens dos trabalhos em grande, se tratou de os não promover, e de suprimir o emprego do Operário, o que teve lugar na Congregação da Faculdade de Filosofia e de Medicina de 15 de fevereiro de 1785 em que se deliberou que até superior resolução se não cuidasse nos trabalhos em grande, e que em vez do Operário se empregasse um Opositor com $200 \$ 000$ reis de ordenado para dirigir somente os trabalhos das experiências, e ensinar os Praticantes, e que além disso fosse o Substituto extraordinário da Cadeira. Sua Majestade confirmou esta deliberação, ordenando em Aviso de 14 de maio de 1787: que não houvesse o mencionado Operário, visto poder-se aquele lugar suprir por um Demonstrador da Faculdade conforme o parecer do Excelentíssimo Prelado. Em quanto ao Mapa das receitas e despesas, não se pode cumprir o que manda a Portaria. Porque os objetos de maior valor que têm vindo para o estabelecimento, como substâncias compradas por junto, máquinas e vários utensílios, têm sido pagos pela Junta da Real Fazenda, sem o Lente de Química saber qual foi a sua importância; e daquelas compras de pouco valor, que têm sido feitas por Ordem do mesmo Lente, não se tem feito escrituração regular, mas organizam-se Folhas que se dirigem à sobre dita Junta, e só desta Repartição se pode tirar um Mapa exato de toda a despesa feita no Laboratório. Como o Laboratório não trabalha em grande, é de mui pequeno momento a venda dos produtos, esta se tem limitado a algumas águas minerais, e a poucos objetos além deste, segundo o conhecimento que tenho da repartição, pelos muitos anos, em que fui Demonstrador dela, esse pequeno produto, de que não há escrituração, costuma empregar-se em algumas compras que por esse motivo não entram em Folha (...). Esta repartição não tem mais do que um Oficial, que vem a ser o Guarda. As suas obrigações interinas são abrir e fechar as portas, ministrar as substâncias e utensílios, que hão de servir nas experiências, arrecadar os preparados, cuidar da limpeza das máquinas e vasos grandes e ajudar n’alguns trabalhos. É obrigado a residir no Estabelecimento em todos os dias que não são de Preceito de Missa, desde a primeira hora da manhã até ao meio dia, e da primeira da tarde até à noite (inclusivamente no tempo de férias). Este Oficial não tem Regimento como representei a Vossa Excelência, e tendo eu sido encarregado de o fazer o entreguei ao Secretário da Congregação, para ser examinado pelos Vogais dela, e não está ainda aprovado. Há um trabalhador jornaleiro, que se emprega nos serviços mais pesados como rachar lenha e conduzir objetos ao Laboratório o qual reside no estabelecimento nos dias de trabalho pela manhã até à noite» [15].

Durante, praticamente, o período da sua diretoria, apenas são possíveis pequenas reparações no edifício, a aquisição de algum material de vidro como balões, pipetas, copos, tubos de ensaio, etc., e combustível para o funcionamento dos fornos [16].

\section{Décadas de 1840 a 1860}

Reforma de 1844: Criação das cadeiras de Química Inorgânica e de Química Orgânica e Análise Química

A Reforma de 1836 de Passos Manuel cedo se revelou pouco profunda relativamente às expetativas de desenvolvimento do ensino teórico e prático nas diversas áreas científicas na Faculdade de Filosofia, com «o gravíssimo defeito do ensino de toda a química em um só ano, e no primeiro do curso, em que os alunos ainda não tinham a capacidade intelectual e o desenvolvimento científico, absolutamente necessário para compreender tão vasta e difícil ciência (...). A química de 1836 já era uma ciência de largos horizontes e vastíssimas aplicações; e a análise química possuía já processos experimentais, muito exatos e rigorosos, que prestavam serviços imensos não só ao estudo das ciências, tanto naturais e médicas, mas também às necessidades da indústria e do comércio. A reforma deixou no silêncio esta parte importante dos estudos da química, o que era uma falta irreparável não só para os alunos da Faculdade mas para os que se destinavam à medicina» [17]. Oito anos depois António Bernardo da Costa Cabral (1803-1889) promoveu uma nova Reforma. Em Congregação da Faculdade de Filosofia de 10 de março de 1843, foi lida a seguinte portaria do Ministério do Reino: «desejando o Governo de Sua Majestade a Rainha promover o melhoramento dos Estudos da Universidade de Coimbra, apresentando às Cortes a proposta de 
Lei, que para isso for conveniente (...). Resolveu-se que se nomeasse uma Comissão para propor ao Conselho o Projeto de reforma da Faculdade, e foram nomeados os Srs. Goulão (António Sanches Goulão (1805-1857)), Antonino Vidal (Antonino José Rodrigues Vidal da Silveira (1808-1879)) e Henrique do Couto (Henrique Couto de Almeida Vale (1807-1868))» [18]. Em Congregação de 8 de abril de 1843, a Comissão apresentou o projeto de Reforma onde recomendava: «1. ${ }^{\circ}$, a criação da cadeira de química orgânica e analise química, conservando a de tecnologia; $2 .^{\circ}$ um curso bienal de física e de química inorgânica no $1 .^{\circ}$ e $2^{\circ}$ anos» [19]. Em 1844, pelo Decreto, de 20 de setembro, foi concretizada uma Reforma que atendeu e sancionou a maior parte das recomendações referidas na proposta da Faculdade Filosofia, ficando o curso com sete cadeiras, dando um maior peso à Química que passa a integrar as especialidades de Química Inorgânica, Química Orgânica e Análise Química e Tecnologia. Foi um avanço importante, que apenas parcialmente satisfez o corpo docente da Faculdade de Filosofia, pois «juntar em uma só cadeira o ensino da química orgânica, análise química e tecnologia é um gravíssimo defeito, porque torna o estudo deficiente e superficial, e constitui um programa impossível de realizar-se. Os progressos da química orgânica são de tal ordem que já é difícil abranger em um só ano o estudo de tão vasta ciência; e de modo nenhum se deve sacrificar a esta acumulação de doutrinas a análise química, ramo da ciência que precisa de ser profundamente professado e com grande desenvolvimento» [20].

\section{Reorganização espacial do Laboratório Químico: o Anfiteatro}

As cadeiras de Química Inorgânica e Química Orgânica, criadas pela Reforma de 1844, instalam-se na Aula de Demonstrações Químicas, o designado “espaço teórico”, mantendo a sua configuração inicial inalterada. Porém, em 9 de dezembro de 1855, «no Laboratório Químico da Universidade de Coimbra, estando presentes o Dr. José Maria de Abreu, Lente catedrático da Faculdade de Filosofia, no impedimento do Diretor do mesmo Laboratório, o Doutor Antonino José Rodrigues Vidal, e o Doutor Joaquim Augusto Simões de Carvalho, Lente Substituto ordinário da mesma Faculdade, servindo de Fiscal, foi posta em praça a Obra de Carpinteiro de umas bancadas que hão de servir para as duas Cadeiras de Química, na sala em que atualmente se liam as lições de Química Orgânica, e cuja obra consta do risco e apontamentos do Mestre das Obras da Universidade (...). Segundo: Que a obra esteja perfeitamente pronta e acabada até quinze de julho (1856), próximo futuro, impreterivelmente» [21]. Uma das mais significativas intervenções produzidas no Laboratório Químico de oitocentos (Figura 1). Foi Antonino José Rodrigues Vidal quem assinou, como diretor, os documentos de despesa, embora na sua biografia não apareça referência à ocupação deste cargo. Foi certo que em 1854-1855, e entre 1856 e 1865, regeu, como Lente, as cadeiras de Química Inorgânica e de Química Orgânica, respetivamente, admitindo-se que neste período tenha ocupado a diretoria do Laboratório, pois em muitas das atas das Congregações realizadas na época, foi designado como tal.

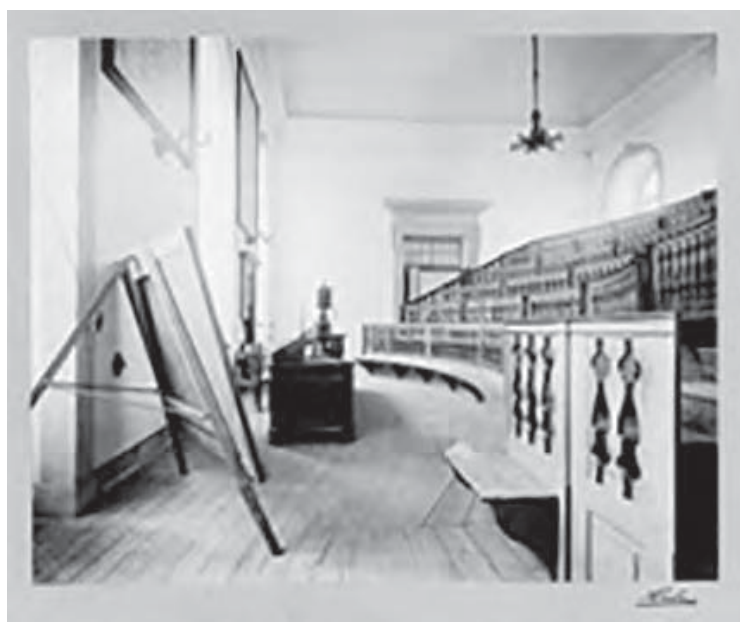

Figura 1 - Anfiteatro do Laboratório Químico (Albumina de Augusto Babone, 1890).

\section{Início da espetroscopia no Laboratório Químico}

Henry Roscoe (1833-1915) na obra Spectrum Analysis (1869) afirma: «Nenhuma das descobertas da ciência moderna atraiu mais atenção ou mais a admiração geral do que os resultados da Análise Espectral para a química» [22]. O percurso tinha começado cerca de 200 anos antes. Em 1671, Isaac Newton (1643-1727) descreve a imagem colorida produzida por um feixe de luz solar ao incidir num alvo, após ter atravessado um prisma de vidro tendo, pela primeira vez, usado a palavra spectrum (= fantasma). Cem anos depois, em 1802, William Hyde Wollaston (17661828) e, em 1814, Joseph von Fraunhofer (1787-1826) procederam a experiências semelhantes usando, todavia, uma fenda muito estreita em vez de um orifício para admissão da luz a estudar, que permitia a formação de linhas ou riscas espectrais de um só comprimento de onda. Estava lançado o início de uma nova técnica de análise química fundamentada na análise das riscas espectrais observadas quando um composto ou elemento era submetido à ação de uma chama. O seu desenvolvimento foi moroso. Um avanço surge com Robert Wilhelm Bunsen (1811-1899). Em 1852 tinha ingressado na Universidade de Heidelberg, sucedendo a Leopold Gmelin (1788-1853). Roscoe inicia com Bunsen estudos sobre a ação química da luz. Para ajudar no trabalho experimental, Roscoe traz de Inglaterra um queimador, modificação do queimador de Argand (Aimé Argand (1750-1803)), muito utilizado nos laboratórios do University College of London. A chama resultante apresentava diversas limitações: era de difícil regulação, muito grande, oscilante, luminosa, com fuligem e apresentava baixa temperatura. Bunsen percebeu que o problema residia no facto da mistura gás/ar ser obtida fora do queimador. Sugeriu então uma solução simples - obter a mistura gás/ar antes da combustão no queimador. Com a colaboração do técnico mecânico da universidade, Peter Desaga (1812-1879?), projetam um bico (ou queimador) que ficou conhecido por "bico de Bunsen”, no qual o gás e o ar são misturados antes da combustão, de modo a alcançar temperaturas elevadas e produzir uma chama não luminosa. No ano de 1859, Bunsen deixa os seus estudos fotoquímicos para se dedicar à análise espectral. O seu colega de universidade e físico Gustave Kirchhoff (1824-1887) sugere-lhe 
que a análise poderia ser mais eficiente se a luz da chama passasse por um prisma, técnica já utilizada por Newton. Desta maneira, empregando as técnicas experimentais de Fraunhofer e o bico de Bunsen, puderam atribuir espetros aos elementos e compostos químicos, estabelecendo assim a Espetroscopia como uma nova área de análise qualitativa e quantitativa [23].

Em finais dos anos 50 e início de 60 do século XIX, dois acontecimentos ocorrem quase simultaneamente no Laboratório Químico. Na Congregação de 29 de julho de 1858, o «lente Jardim (Manuel dos Santos Pereira Jardim (1818-1887)) solicita autorização para que se introduza o gás de iluminação da cidade no mesmo Laboratório, para se empregar nas operações e trabalhos químicos em que for necessário» [24]. Admite-se que a concretização da sua instalação no Laboratório tenha ocorrido durante 18581859, pois em reunião do Conselho da Faculdade de 21 de abril de 1860, Rodrigues Vidal informava o Conselho «de que tinha mandado meter mais alguns bicos de gás no Laboratório, sem ter dado previamente parte ao Conselho, por ser urgente a necessidade daquele melhoramento, decisão aprovada pelo Conselho» [25]. Em 1864, o Laboratório Químico adquire, quatro anos depois do seu invento, um espetroscópio de Bunsen-Kirchoff [26], substituído mais tarde por outro modelo mais elaborado, conservado hoje em museu (Figura 2). Rodrigues Vidal diligencia para a sua instalação, «num dos lados das bancadas [Anfiteatro] e por debaixo delas construiu-se um pequeno gabinete, pintado de preto, para se fazerem experiências de química espetral» [27].
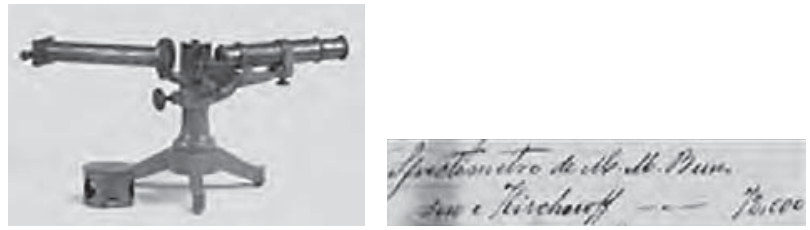

Figura 2 - Espetroscópio de Kirchhoff e Bunsen adquirido pelo Laboratório Químico. (Instrumento inventariado como nº QUI.0001 do MCUC), e respetivo registo de compra (datado de agosto de 1864).

\section{Inventário do Laboratório Químico de 1850 e de 1855}

No início de 1850, por comissão do então Reitor José Machado de Abreu (1794-1357), Fortunato Rafael Pereira de Sena (1793-1887), criou o Inventário do Laboratório Químico da Universidade [28]. Na ante página de rosto, o Reitor escreveu: «este livro há de servir para nele se lançar o Inventário do Laboratório Químico da Universidade ---- 25 de fevereiro do ano de 1850. Dou comissão ao Lente Catedrático Fortunato Rafael Pereira de Sena para rubricar este livro. Coimbra, Paço da Escolas, 25 de fevereiro de 1850. José Machado de Abreu, Reitor». Na folha de encerramento lê-se: «tem este livro duzentas e noventa e cinco folhas, que todas vão por mim rubricadas, de que se fez este termo de encerramento aos 25 de fevereiro de 1850 ---- Dr. Fortunato Rafael Pereira de Sena. Terceiro lente da Faculdade de Filosofia». Das 295 folhas manuscritas, apenas número reduzido foram utilizadas. No Inventário de 1850 referem-se as seguintes rúbricas: "Catálogo das substâncias pertencentes ao Gabinete de Química Inorgânica, coordenadas segundo a Classificação de Orfila (Mathieu Orfila (1787-1853)) na sétima edição dos seus "Elementos de Química” (págs. 1-12); “Catálogo das substâncias pertencentes ao Gabinete de Química Orgânica, classificadas segundo o mesmo autor” (págs. 24-32 verso); "Reserva - Das substâncias pertencentes ao Gabinete de Química Inorgânica” (págs. 46-48); "Reserva - Das substâncias pertencentes ao Gabinete de Química Orgânica” (págs. 70-71); "Inventário - Dos Instrumentos, Máquinas, Aparelhos, vasos de vidro, de metal e vários outros utensílios” (págs. 83-97); “Livros” (págs. 98-98 verso). O livro contém, também, o Inventário - Do Laboratório Químico Ano de 1855, com registos relativamente às seguintes rubricas: "Química Orgânica - Classificações”; "Reserva” (págs. 126-134, 134-140 verso); "Utensílios de Vidro”; "Utensílios de Barro” (págs. 142-144; 146-147 verso); "Diversos Instrumentos - De vidro, metal e madeira” (págs. 148-160).

O Inventário revela o provimento de material do Laboratório Químico desde, provavelmente, Tomé Rodrigues Sobral (1759-1829) até, pelo menos, ao ano de 1869. De facto, encontra-se referência a algumas máquinas e instrumentos necessários para o serviço do Laboratório que Tomé Sobral mandou encomendar a José Joaquim de Miranda (?-?), mestre maquinista da Universidade, designadamente um "pirómetro de Wedgwood com sua caixa” [29]; um "goniómetro"; e "uma balança de ensaio (Figura 3 (a)) [30]. Tomé Sobral referiu-se a Joaquim de Miranda de modo elogioso: «Por tudo sou obrigado não só a informar do merecimento do referido José Joaquim de Miranda, mas até a desejar que ele seja dignamente premiado e animado a empregar o seu conhecido génio muito capaz de fazer diminuir muito e cessar em grande parte a nossa dependência dos Artistas ou Maquinistas Estrangeiros para a Construção de quaisquer instrumentos necessários na prática das Ciências Experimentais. Coimbra e Laboratório da Universidade em 17 de agosto 1805. Tomé Rodrigues Sobral» [31].

Há também registo de "um desinfetador de Morveau”, peça eventualmente fabricada no Laboratório Químico e utilizado por Rodrigues Sobral no surto de peste que se alastrou em Coimbra em agosto de 1809, e referência a diversos instrumentos designadamente: "um calorímetro de Lavoisier ", "um gasómetro do mesmo autor para a síntese da água” (Figura 3 (b)), "um higrómetro de cabelo”, "um termómetro diferencial de Leslie”; “um areómetro de Cartier”, "um areómetro centesimal de Gay-Lussac”, “um barómetro de Clarke com seu termómetro”; assim como "um aparelho elétrico para sínteses da água, de vidro”, "dois eudiómetros de Fontana”, "um dito de Volta”, “duas tinas pequenas da pilha galvânica”, "sessenta e oito pares de lâminas de cobre e zinco pertencentes ao aparelho galvânico em taças”, “um aparelho Carré para congelação da água” [32]. No Inventário de 1855 há registo de inúmeros aparelhos assinalados com uma cruz a lápis. Pode ler-se: «todos os Instrumentos notados com este sinal + feito a lápis passarão para a Repartição do Gabinete de Física em 21 de maio de 1869 (Ass. Cunha)» [33]. Desconhecem-se as razões da passagem destes instrumentos para o Gabinete de Física. É possível encontrar numa ou outra ata da Congregação da Faculdade de Filosofia, onde se refere a permuta de mobiliário e mesmo de instrumentos entre os diversos estabelecimentos. Admite-se que tal decisão seja devida à falta de escassez de meios e se tenha tornado prática comum dentro da Faculdade de Filosofia. 

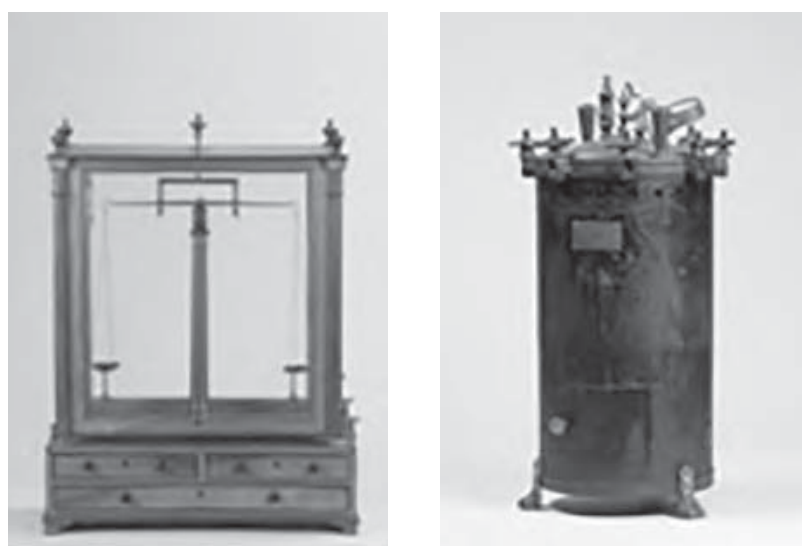

Figura 3 - (a) Balança de ensaio (instrumento inventariado como $n^{\circ}$ FIS 0654 MCUC) [46]; (b) Gasómetro de Lavoisier (instrumento inventariado como $n^{\circ}$ QUI.0078 MCUC).

\section{A biblioteca da Faculdade de Filosofia e a biblioteca privada do Laboratório Químico}

Com a supressão das ordens religiosas e, passando para o domínio do Estado os bens que possuíam, em 4 de junho 1834, o Vice-Reitor da Universidade, José Alexandre Campos e Almeida, apresentou ao Governo um pedido para que as livrarias destas casas fossem entregues à Universidade, o que veio acontecer por Portaria do Ministério do Reino de 9 de junho. Por despacho do Vice-Reitor, de 24 de outubro, foram nomeados dois lentes Joaquim dos Reis (1794?) e Adrião Pereira Forjaz de Sampaio (1810-1874), «para procederem de inteligência com o bibliotecário, à receção e inventário de todas aquelas livrarias. Já então estava nomeado bibliotecário da Universidade o Lente de Prima da Faculdade de Leis, Manuel de Serpa Machado (1834-1858)» [34].

Entre as diversas casas desocupadas pelos religiosos, em condições de servir de depósitos, nenhumas tão próprias, para este fim, como as amplas salas do andar superior do Colégio das Artes. Para aí foram transferidas, por diligências da referida Comissão, quase todas as mencionadas livrarias, em número superior a cem mil volumes; algumas, cerca de vinte e tantos mil volumes ao todo, passaram diretamente para o edifício da biblioteca da Universidade, ficando desde logo incorporados nesta.

Na Congregação da Faculdade de 4 de março de 1852, foram feitas as propostas seguintes: «convindo aumentar a biblioteca especial da Faculdade, com a aquisição de algumas obras, de que haja exemplares em duplicado no depósito de livros das extintas ordens religiosas, atualmente existente no edifício do Colégio das Artes, proponho: $1 .^{\circ}$ que em Conselho da Faculdade se nomeie uma Comissão que se encarregue de proceder à escolha das ditas obras, preferindo as que mais convierem ao estudo das ciências físicas e naturais, e de as fazer transportar para o local da biblioteca do Museu, 2. ${ }^{\circ}$ que seja concedida autorização pelo mesmo Conselho para os respetivos professores ali guardem alguns jornais estrangeiros, que mais úteis lhe pareçam para o ensino das suas cadeiras, e com eles poder ser enriquecida a mesma biblioteca» [35]. Em 15 de dezembro, «foi autorizado a gastar pelo cofre da Faculdade a quantia necessária para arranjo da biblioteca da Faculdade» [36].
Entretanto, o Hospital da Conceição e da Convalescença, instalado na Praça da cidade (hoje Praça do Comércio), foi transferido, por determinação do Marquês de Pombal, em 19 de março de 1779, para o edifício do Colégio de Jesus. A partir de 1834, mudado para o edifício do Colégio de S. Jerónimo. Na sequência da Portaria do Ministério do Reino de 27 de outubro de 1853, em Congregação de 1 de dezembro, foi decidido «aplicar o edifício do antigo Hospital a parte necessária para nele se estabelecer o Museu» [37]. Encarregou-se das obras de transformação do 1. ${ }^{\circ}$ andar do Colégio de Jesus, entre novembro de 1857 e 30 de junho de 1859, José Maria de Abreu. Em 19 de julho de 1858, numa visita aos Estabelecimentos da Faculdade, «inspecionando as obras que recentemente se tem feito no edifício do antigo Hospital da Conceição anexo ao Museu, tomaram-se as seguintes decisões (...): $5 .^{\circ}$ - que logo que esteja concluída a galeria do antigo hospital, para ela passe a coleção de antiguidades e raridades do Museu; e que, tanto que esta mudança esteja feita, se coloque nas salas, onde estavam aquelas coleções, a biblioteca da Faculdade aproveitando-se as mesmas estantes em que ela se acha atualmente na sala inferior do Museu, que fica destinada para o serviço do Gabinete de Física, e a imediata contigua à aula de Matemática para o serviço de Agricultura» [38].

O sucesso do pedido às livrarias dos conventos e colégios da cidade foi comprovado pelos livros mais antigos da área da Química, existentes na atual biblioteca do Departamento de Química da Universidade de Coimbra, oriundos do Convento de Santa Cruz, de que são exemplos: Chymia in artis formam redacta: sex libris comprehensa, de Guerneri Rolfincii (1599-1673), 1686, (Figura 4 (a)) [39]; Lexicon chymico-pharmaceuticum: in duas partes distinctum ubi pars prior continet selectos processus chymicos potissimum hactenus magis usuales \& originaliter è Medicorum, non verò Pharmacopolarum Laboratoriis prodeuntes pars altera de Johannis Helfrici Jungken (1648-1726), 1716, (Figura 4 (b)) [40]; Lexeci Chimico Pharmaceutici paras alters continens Composita tàm Galenica, quàm Galenico-Chimica, 1737, de autor desconhecido [41]; Cours de Chymie [Cours de chymie: contenant la maniere de faire les operations qui sont en usage dans la medecine, par un methode facile; avec des raisonnements sur chaque operation, pour l'instruction de ceux qui veulent s'appliquer a cette science], do químico francês Nicolas Lémery (1645-1715), 1675, e que conheceu 13 edições; Elementa Chemiae: quae anniversario labore docuit, in publicis, privatis que, scholis, do médico e químico holandês Hermannus Boerhaave (1668-1738), 1732 [42]. Na rúbrica Livros, do Inventário de 1850, além dos citados, há registo de Éléments de Chimie aplique à l'a medicine e aux arts, par M. Orfila (dois volumes) [43], as obras do químico francês Henri Victor Regnault (1810-1878), designadamente Premiers Éléments de Chimie [44] e Cours Élémentaire de Chimie (quatro volumes) [45], e das revistas Annales de Chimie, 89 volumes (volume 1, 1789), Journal de Pharmacie et de Chimie, 14 volumes (volume 1, 1842), Journal de Pharmacie et de Chimie, mais oito volumes», que entretanto foram enviados para a Livraria da Faculdade. De facto, a biblioteca do Laboratório Químico, desde cedo, foi considerada pelos seus professores como peça indispensável de trabalho. 


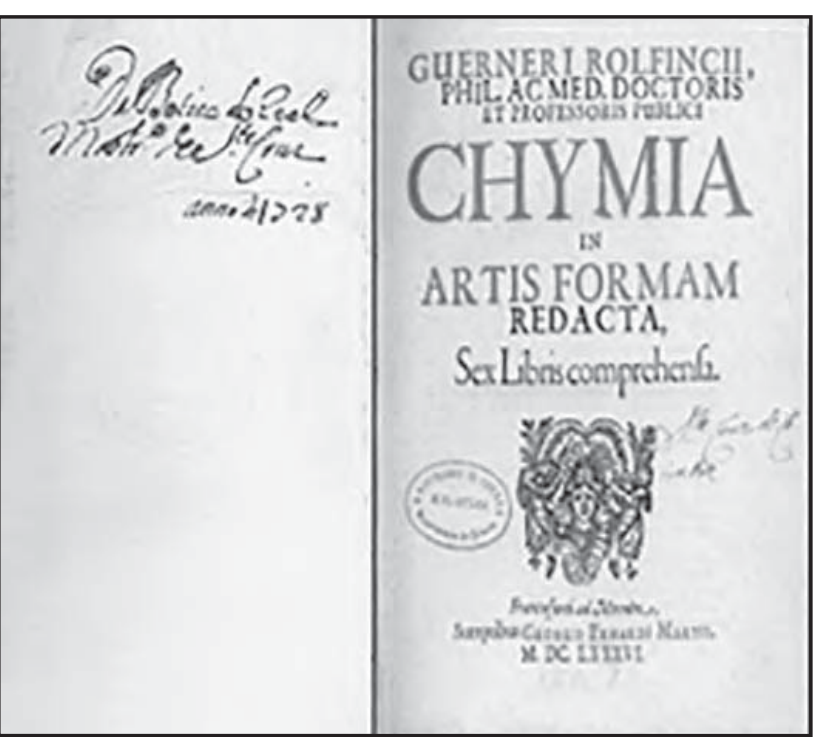

(a)

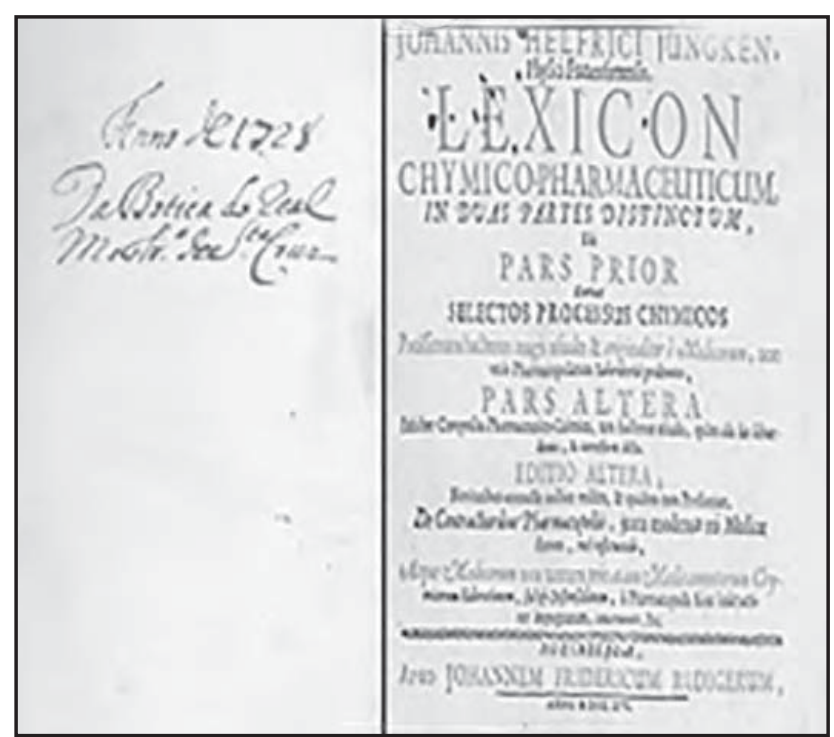

(b)

Figura 4 - Frontispício do livro (a) G. Rolfincii, Chymia in Artis Formam Redacta, Sex Libris comprehensa (1686); (b) Johannis Helfrici Jungken, Lexicon Chymico-Pharmaceuticum, in duas partes distintum (1716).

\section{Referências}

[1] Arquivo da Universidade de Coimbra (A.U.C.), Actas das Congregações da Faculdade de Filosofia, 1772-1820, Acta de 25-XI-1805, 300.

[2] Idem, Acta de 24-V-1806), 302.

[3] Idem, Acta de 12-VII-1806, 307.

[4] Idem, Acta de 19-XII-1811, 334.

[5] Idem, Acta de 15-I-1812, 335, 336.

[6] Idem, Acta de 31-VII-181, 359.

[7] A. Balbi, "Essai statistique sur le royaume de Portugal et d'Algarve: Comparé aux outres États de l' Europe”, Tome II, Paris, Chez Rey et Gravier, Libraires, 1822, (lix)

[8] A.U.C., Actas das Congregações da Faculdade de Filosofia, 1772-1820, Acta de 11-VII-1818, 375.

[9] R. Fernandes, Luis da Silva Mousinho de Albuquerque e as reformas de ensino em 1835-1836, in Boletim da Biblioteca da Universidade de Coimbra 36 (1983) 234.

[10] Idem, 242, 243.

[11] Representação da Universidade de Coimbra dirigida às Câmaras Legislativas da Nação Portuguesa, in M. A. Rodrigues, "A Universidade de Coimbra, Figuras e factos da sua história”, vol. I, Tipografia do Carvalhido, Porto, 2007, 771-772, 774-779, 789-790.

[12] J.M. Abreu, "Legislação Académica, desde os estatutos de 1772 até ao fim do ano de 1850”, Coimbra, Imprensa da Universidade, 1851, 96.

[13] Idem, 104, 105.

[14] A.U.C, Processo do Prof. Joaquim Franco da Silva (caixa 322, documento $\mathrm{n}^{\circ}$ 208).

[15] Idem.

[16] A.U.C, Actas das Congregações da Faculdade de Filosofia, 1803-1840, Acta de 26-VII-1825, 109, 109v.

[17] J. A. Simões de Carvalho, "Memoria Historica da Faculdade de Philosophia”, Coimbra. Imprensa da Universidade, 1872, 46, 47.

[18] A.U. C, Actas das Congregações da Faculdade de Filosofia, 1840-1859, Acta de 10 de março de 1843, p.48.

[19] Idem, Acta de 8 de abril de 1843, $49 \mathrm{v}-54 \mathrm{v}$.
[20] J.A. Simões de Carvalho, ob. cit., 48-49.

[21] A.U.C., Termo de arrematação. Administração e Contabilidade - Estabelecimentos Diversos - Documentos de Despesa julho 1855-1857 (II, $1^{\text {a }} \mathrm{D}-7-3-4$ ).

[22] H. Rascoe, "Spectrum Analysis, Six Lectures, Delivered in 1868, Before the Society of Apothecaries of London” 1885 London, Macmillan \& Co.

[23] G. Kirchhoff , R. Bunsen, Chemical Analysis by Observation of Spectra, in "Annalen der Physik und der Chemie", 110 (1860), 161-189.

[24] A.U.C, Actas da Congregação de Filosofia 1856-1860, Acta de 29 de julho de 1858.

[25] Idem, Acta de 21 de abril de 1860.

[26] M.E.S. Eusébio, M.L.P. Leitão, J.S. Redinha, Apontamentos da história do Laboratório Químico da Universidade de Coimbra. A Evolução da espectroscopia, in "Obra Científica da Professora Doutora Maria Luísa Plana Leitão, Volume 2 - Textos Didácticos, Coimbra, Imprensa de Coimbra, pp. 357, 358.

[27] M.F. Leão, Laboratorio de Chimica (1870), in J. Simões de Carvalho, ob.cit., 179-191.

[28] Inventário do Laboratorio Chimico (1850) registado na biblioteca do Departamento de Química como Catálogo das substâncias pertencentes ao Gabinete de Chimica Inorgânica, coordenadas segundo a Classificação de Orfila na sétima edição dos seus elementos de chimica [Manuscrito].

[29] Idem, 86.

[30] Idem, 84.

[31] I. Malaquias, M.F. Thomaz, Aspectos do desenvolvimento do ensino experimental em Portugal e seu contributo para a propagação da revolução científica, in "Actas do $1 .{ }^{\circ}$ Congresso Luso-Brasileiro de História da Ciência e da Técnica”, Universidade de Évora e Universidade de Aveiro, 22 a 27 de outubro, 2000, 139, 140.

[32] Inventário do Laboratorio Chimico, $87 \mathrm{v}-96 \mathrm{v}$.

[33] Idem, 198. Nota: O registo do apetrechamento terá ocorrido durante a direção de Ferreira Leão iniciada em 1865, pois a assinatura "Cunha" refere-se a José Pereira da Cunha, à época, desempenhando as funções de Guarda de Gabinete. 
[34] B. S. Pimentel, Breve notícia da livraria da Universidade de Coimbra, in "Vila Maior, visconde - Exposição succinta da organização actual da Universidade de Coimbra precedida de uma breve notícia histórica d'este estabelecimento”. Coimbra. Imprensa da Universidade, 1877, p. 470-508.

[35] A.U.C, Actas das Congregações da Faculdade de Filosofia, 1850-1856, Acta de 4 de março de 1852, pp. 21, 21 v.

[36] Idem, Acta de 15 de dezembro de 1852, p. 34.

[37] Idem, Acta de 1 de dezembro de 1853, pp. 60 v, 61

[38] A.U.C, Actas das Congregações da Faculdade de Filosofia, 1856-1861, Acta de 19 de julho de 1858, pp. 36 v, 37

[39] G. Rolfincii, "Chymia in artis formam redacta: sex libris comprehensa”, Gevevea [s.l.], 1686; UC. Biblioteca do Departamento de Química.

[40] J.J. Helfrich, "Lexico Chimico Pharmaceutico pars Itera contiens Composita tàm Galenica, quàm Galenico-Chimica”, Norimbergue, 1716; UC. Biblioteca do Departamento de Química.

[41] Lexici Chimico Pharmaceutici pars altera continens Composita tàm Galenica, quàm Galenico-Chimica (autor desconhecido) (1737); UC: Biblioteca do Departamento de Química.

Nota: as citações em Português foram convertidas para a grafia atual.
[42] H. Boerhaave, "Elementa Chemiae: quae anniversario labore docuit, in publicis, privatis que, scholis, Lugduni Batavorum”, 1732, 2 vols; UC: Biblioteca do Departamento de Química.

[43] M. Orfila, "Éléments de Chimie aplique à l'a medicine e aux arts”, Paris, Labé, Masson et Cie, 1843, 2 vols; UC. Biblioteca do Departamento de Química.

[44] M. V. Regnault, “Premiers Éléments de Chimie: a l'usage des facultés des etablissements d'enseignement secondaire, des écoles normales et des écoles industrielles”, Paris, Langlois et Leclercq, 1851; UC. Biblioteca do Departamento de Química.

[45] M.V. Regnault, "Cours élémentaire de chimie”, Paris, Victor Masson, 1851, 4 vols; UC. Biblioteca do Departamento de Química.

[46] Esta deverá ser a balança que existe atualmente no Gabinete de Física, semelhante a uma outra também aí existente, da autoria de W. \& S. Jones, que havia sido construída em Inglaterra segundo o modelo da de João Jacinto Magalhães. Tal balança não se encontrava catalogada nos índices conhecidos, admitindo-se que poderá ser a construída por Joaquim de Miranda a pedido de Sobral Rodrigues, in Isabel Malaquias e Manuel F. Thomaz, ob. cit., nota 17 da p. 139.

Atualidades Cientíicas

\section{Polímeros superabsorventes a partir de amido de milho}

Os polímeros superabsorventes (SAPs) são uma classe de polímeros de elevado peso molecular contendo um grande número de grupos hidrofílicos capazes de absorver grandes quantidades de água ou soluções aquosas. Eles são usados principalmente em produtos de cuidados higiénicos (por exemplo, fraldas) mas também na agricultura e floresta, medicina ou conservação de alimentos. Os polímeros superabsorventes têm sido habitualmente produzidos a partir da polimerização do ácido acrílico ou derivados. Numa perspetiva de desenvolvimento económico e social sustentável, os polímeros biodegradáveis têm atraído considerável atenção pela possibilidade de substituírem os polímeros sintéticos, que causam evidentes problemas de poluição. Neste sentido, têm sido estudados os chamados polímeros superabsorventes verdes obtidos a partir de biomassa, incluindo amido, celulose ou quitosana, por exemplo.

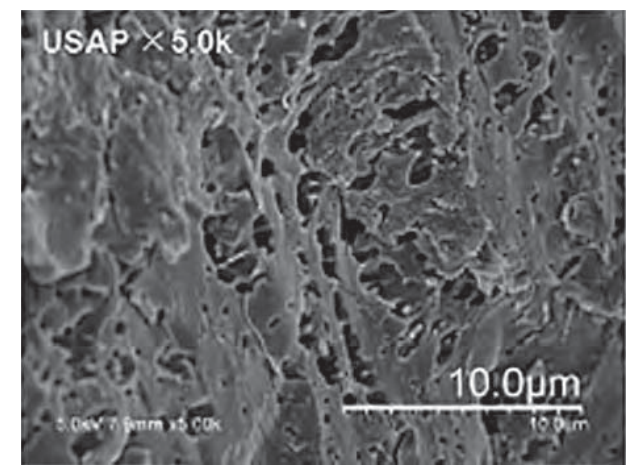

Recentemente, Bin Li, da Universidade Agrícola de Huazhong, Wuhan, China e colegas desenvolveram um processo de síntese one-pot de um polímero superabsorvente baseado em amido de milho/ureia (USAP). A uma solução alcalina de amido, foi adicionado ureia (agente de formação de poros e formação de grupos amino), ácido acrílico como monómero, persulfato de amónio como iniciador e $N, N^{\prime}$-metilenobisacrilamida como agente reticulante. O polímero foi obtido na forma de um hidrogel que foi seco antes dos testes subsequentes. O material resultante mostrou possuir uma absorção de água de 2704 g/g para a água destilada, 100 g/g para uma solução salina fisiológica e 96 g/g para urina artificial. Cinco tipos de polímeros à base de amido/ureia foram sintetizados com êxito com excelentes capacidades de absorção de água, revelando que o método one-pot utilizado será conveniente para uma potencial aplicação industrial.

\section{Fontes:}

Superabsorbents made from corn starch, http://www.chemistryviews.org/details/news/10515724/Superabsorbents_ Made_from_Corn_Starch.html?elq_mid=17621\&elq_cid=3941189 (Acedido em 03/05/2017)

T.G. Liu, Y.T. Wang, J. Guo, T.B. Liu, X. Wang, B. Li. One-step synthesis of corn starch urea based acrylate superabsorbents. J. Appl. Polym. Sci. 134 (2017) 45175.

Paulo Mendes (pjgm@uevora.pt) 